\title{
Sorption and Degradation Capacity of Natural Estrogens in Freshwater Environmental System in Japan
}

\author{
Reni Desmiarti ${ }^{1,2} \&$ Fu-Sheng $\mathbf{L i}^{3}$ \\ ${ }^{1}$ Department of Chemical Engineering, \\ Bung Hatta University, Padang, Indonesia \\ ${ }^{2}$ Environmental Research Center, Bung Hatta University, Padang, Indonesia \\ ${ }^{3}$ River Basin Research Center, Gifu University, Japan \\ Email: desmiarti@yahoo.com
}

\begin{abstract}
The sorption and the degradation capacity of natural estrogens in freshwater environmental system in Japan were performed. Batch experiments were examined in water-sediment suspensions using six layers of sediment under aerobic and anaerobic conditions. The results indicated that the water-sediment partition coefficient of $\mathrm{E} 1\left(\mathrm{~K}_{\mathrm{d}}^{\mathrm{E} 1}\right)$ was higher than $\mathrm{E} 2\left(\mathrm{~K}_{\mathrm{d}}^{\mathrm{E} 2}\right)$. The degradation rate of E1 $\left(k_{\mathrm{E} 1}\right)$ was smaller than $\mathrm{E} 2\left(k_{\mathrm{E} 2}\right)$. Under aerobic and anaerobic conditions, $\mathrm{E} 1$ was formed from E2. The degradation rate of E2 $\left(k_{\mathrm{E} 2}\right)$ from the surface to bottom of sediment layers was estimated fell in the range from 0.114 to $0.026 \mathrm{~h}^{-1}$ and 0.05 to $0.014 \mathrm{~h}^{-1}$ under aerobic and anaerobic conditions, respectively.
\end{abstract}

Keywords: degradation; natural estrogens; sediment; sorption; water environment.

\section{$1 \quad$ Introduction}

Natural estrogens as emerging environmental micro-contaminants are greatly concerned because of their potential adverse effects on ecosystems and human health. Compared to alkylphenols, the estrogenic potency of natural estrogens is much stronger. The presence of natural estrogens such as 17 $\beta$-estradiol (E2) and estrone (E1) has been confirmed in water and sediment mud phases of most natural water environment systems [1,2]. Previous studies had revealed the presence of E2 in water and sediment phases at levels lower than E1 [3,4]. Peck, et al. [4] studied the estrogenic activity of sediments of both upstream and downstream of a major sewage treatment plant (STP) discharged in two England river sources and found the estrogenic activity was caused by E1 and a small amount of E2. However, information on the behavior of natural estrogens in fresh water environmental systems is scarce, where both sorption and degradation may play significant roles. Thus, this study investigated sorption and degradation of E2 and E1 in water-sediment suspensions from a freshwater reservoir. 


\section{$2 \quad$ Materials and Methods}

\subsection{Sediment and Water}

The sediment and water were collected from Ushikubiri Reservoir, a prereservoir of the Miharu Dam located in the northeastern Fukushima prefecture, Japan. Sediment was collected using a gravity core sampler with an internal diameter of $4 \mathrm{~cm}$ and a length of $50 \mathrm{~cm}$. Collected cores were transported to the laboratory using a core container which was consistently supplied with nitrogen to prevent sediment from being oxidized by air. In the laboratory, the sediment portion with a thickness of about $(30-35 \mathrm{~cm})$ was sliced vertically from its top into $2 \mathrm{~cm}$ thickness layers. Totally, fifteen sediment layers were obtained. For the purpose of sorption studies, freeze-dried sediment samples were used. These dried sediments were stored at $5^{\circ} \mathrm{C}$ and sterilized in a $105^{\circ} \mathrm{C}$-controlled oven for one hour prior to sorption experiment. Water sample was transported to the laboratory in cool and was stored immediately in the dark at $5^{\circ} \mathrm{C}$ prior to use.

\subsection{Sorption Experiments}

Batch sorption experiments of E2 and E1 were examined using six sliced sediment layers. The experiments were done in a temperature-controlled room at $20^{\circ} \mathrm{C}$ by batch equilibrium sorption method. After sterilization in an oven $\left(110^{\circ} \mathrm{C}, 3\right.$ hours $), 2 \mathrm{~mL}$ of filtered water $(0.2 \mu \mathrm{m}$ PTFE membrane filter) was added into each $5 \mathrm{~mL}$ glass vial following the addition of $0.2 \mathrm{~g}$ of dried sediment. The initial concentrations for E2 and E1 were set at 5, 10, 30, 50 and $100 \mu \mathrm{gL}^{-1}$. Sorption was equilibrated by shaking for 24 hours. After equilibration, each vial was centrifuged at $3500 \mathrm{rpm}$ for 10 minutes and the supernatant was filtered through a $0.45 \mu \mathrm{m}$ membrane filter. The obtained filtrate was subjected to analysis using an Agilent 1100 series liquid chromatography/mass spectrometry (LC/MSD) system (HP1100MSD; CA, USA).

\subsection{Degradation Experiments}

Batch degradation experiments of E2 were also examined using six sliced sediment layers. The experiments were performed using glass reactor $(500 \mathrm{~mL}$ flasks sealed with silicon plugs) placed on water-batch shakers at water temperature of $20^{\circ} \mathrm{C}$ under aerobic and anaerobic conditions. $2 \mathrm{~g}$ of wet sediment and $300 \mathrm{~mL}$ of filtered water $(0.2 \mu \mathrm{m}$ PTFE membrane filter) were added to each reactor, the stock solution of E2 was spiked to obtain initial E2 concentration at $15 \mu \mathrm{gL}^{-1}$. The reactors were shaken $(120 \mathrm{rpm})$ throughout the experiment (up to 150 hours) to ensure a homogeneous sediment suspension. The mixed liquor suspended solids (MLSS) in flasks ranged from 2550 to 2830 $\mathrm{mgL}^{-1}$. During batch experiments, dissolved oxygen (DO) in suspensions was 
maintained at around $8.5 \mathrm{mgL}^{-1}$ and $0 \mathrm{mgL}^{-1}$ under aerobic and anaerobic conditions, respectively. For each sampling, $10 \mathrm{~mL}$ of the suspensions was taken into a $10 \mathrm{~mL}$ centrifuge tube and centrifuged immediately at $3500 \mathrm{rpm}$ for 3 minutes. Then, following prompt filtration of the supernatant through a prewashed $0.45 \mu \mathrm{m}$ PTFE membrane filter (Toyo Roshi, Japan), the obtained filtrate was subjected to analysis using the LC/MSD system.

\section{$3 \quad$ Results and Discussions}

\subsection{Sorption on Sediment}

The relation between the liquid and the solid phase concentrations was described using the linear isotherm.

$$
\mathrm{S}=K_{d} \mathrm{C}
$$

Where $\mathrm{S}$ is the concentration of E2 or E1 sorbed on the sediment $\left(\mu \mathrm{gg}^{-1}\right)$; $\mathrm{C}$ is the liquid phase concentration $\left(\mu \mathrm{gL}^{-1}\right) ; K_{d}$ is the water-sediment partition coefficient $\left(\mathrm{Lg}^{-1}\right)$. The determined $K_{d}$ values for all sliced sediment layers are shown in Figure 1. This figure shown that in each layer of sediments, E1 revealed higher sorption capacity than E2. The sorption capacity depended on the physicochemical properties of the targeted compounds. Less polar targeted compounds tend to have higher sorption capacity on sediments.

Previous studies have shown that the sorption capacity of compounds depends on the carbon content of soil $[5,6]$. They found that the sorption capacity increased with increasing of the organic carbon of soil. Therefore, $K_{d}$ values were further calibrated by the organic carbon content of sediment. Comparisons the calibrated $K_{d}$ values (organic carbon partition coefficient, $K_{o c}$ ) of E2 and E1 with literature values are summarized in Table 1 . The average organic carbon partition coefficient of E2 estimated in the present study $\left(1.34 \mathrm{Lg}^{-1}-\mathrm{C}\right)$ is $1.41 \mathrm{o}$ 2.15 folds lower than that estimated for a surface soil $[5,6]$. For E1, the average organic carbon partition coefficient estimated in the present study $\left(1.44 \mathrm{Lg}^{-1}-\mathrm{C}\right)$ is also 1.15 folds lower than that estimated for a surface soil $\left(1.66 \mathrm{Lg}^{-1}-\mathrm{C}\right)$ (Das et al., 2004). This difference was most likely due to the differences in the carbon content of the sorbent. Table 1 was also shown that a trend of enhanced sorption capacity with increases organic carbon content of the studied materials was not apparent. 


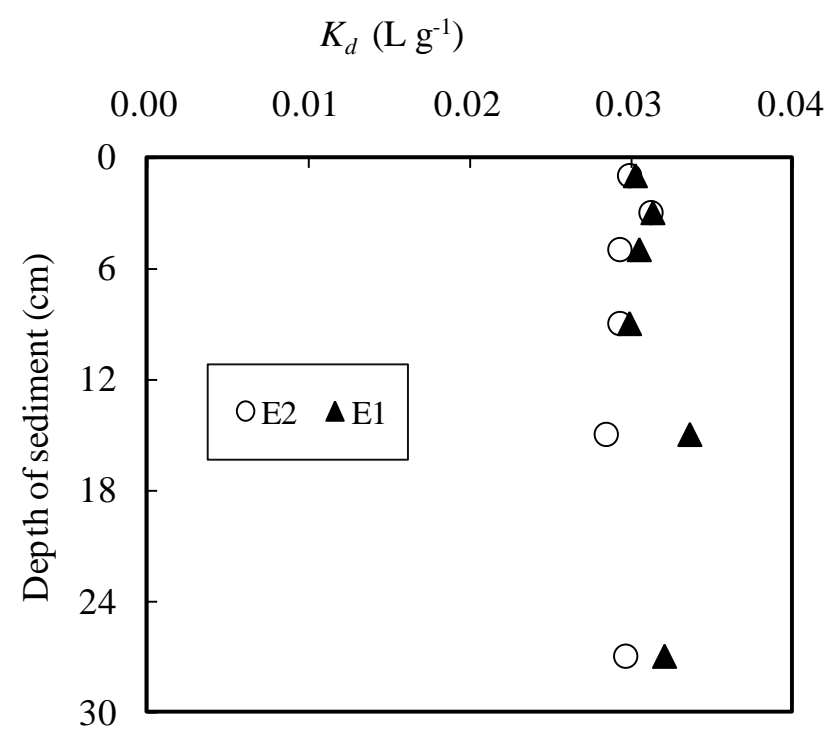

Figure 1 Changes of the water-sediment partition coefficient of E2 and E1 along the vertical direction of the sediment core.

Table 1 Comparisons of the organic carbon partition coefficient of E2 and E1 on sediment with literature values.

\begin{tabular}{|c|c|c|c|c|c|c|c|}
\hline \multirow{3}{*}{ Sediment source } & \multicolumn{2}{|c|}{$\begin{array}{c}\text { Organic carbon } \\
\text { partition } \\
\text { coefficient } \\
\end{array}$} & \multicolumn{4}{|c|}{ Properties of sediment } & \multirow{3}{*}{ References } \\
\hline & $\mathbf{K}_{\mathrm{oc}}{ }^{\mathrm{E} 2}$ & $\mathbf{K}_{\mathrm{oc}}^{\mathrm{E1}}$ & Sand & Silt & Clay & $\begin{array}{c}\text { Total } \\
\text { OC }\end{array}$ & \\
\hline & $\mathrm{Lg}^{-1}-\mathrm{C}$ & $\mathrm{Lg}^{-1}-\mathrm{C}$ & $\%$ & $\%$ & $\%$ & $\%$ & \\
\hline \multirow{2}{*}{$\begin{array}{l}\text { Fresh water sediment } \\
\text { Surface soil of drummer } \\
\text { salty clay loam }\end{array}$} & 1.62 & 1.55 & 93.9 & 0.0 & 6.1 & 0.2 & \multirow{2}{*}{ [6] } \\
\hline & 2.88 & 1.66 & 13.0 & 65.8 & 21.2 & 2.9 & \\
\hline $\begin{array}{l}\text { Surface soil of cecil } \\
\text { sandy loam }\end{array}$ & 1.89 & - & 61.4 & 16.7 & 20 & 0.6 & [3] \\
\hline Reservoir sediment & 1.34 & 1.44 & 0 & 75.2 & 24.8 & 2.2 & This study \\
\hline
\end{tabular}

\subsection{Degradation in Water-Sediment Suspensions}

The concentration profiles of spiked E2 and its byproduct E1 in batch reactors under aerobic and anaerobic conditions are illustrated in Figure 2 using the sediment layer at the depth of $14-16 \mathrm{~cm}$. 


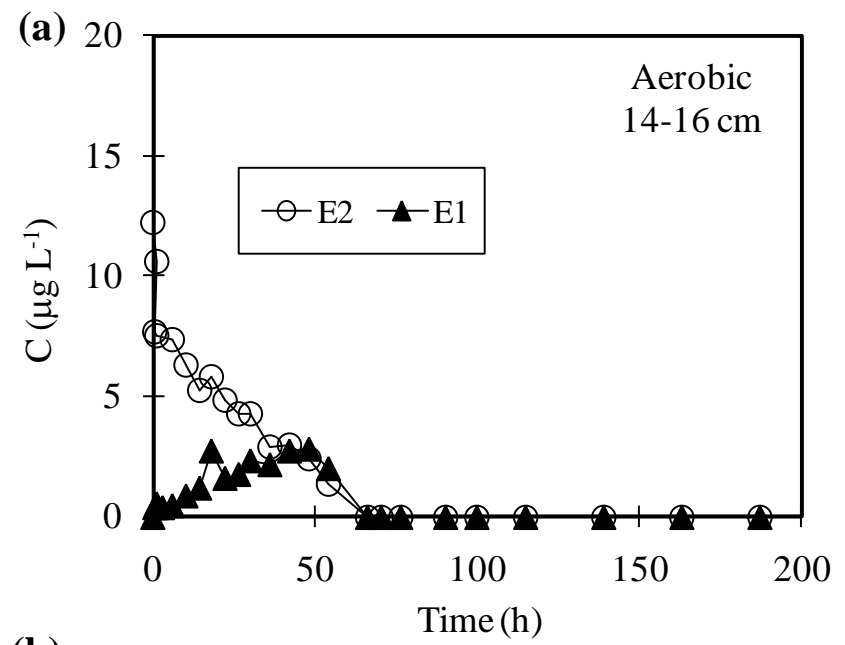

(b)

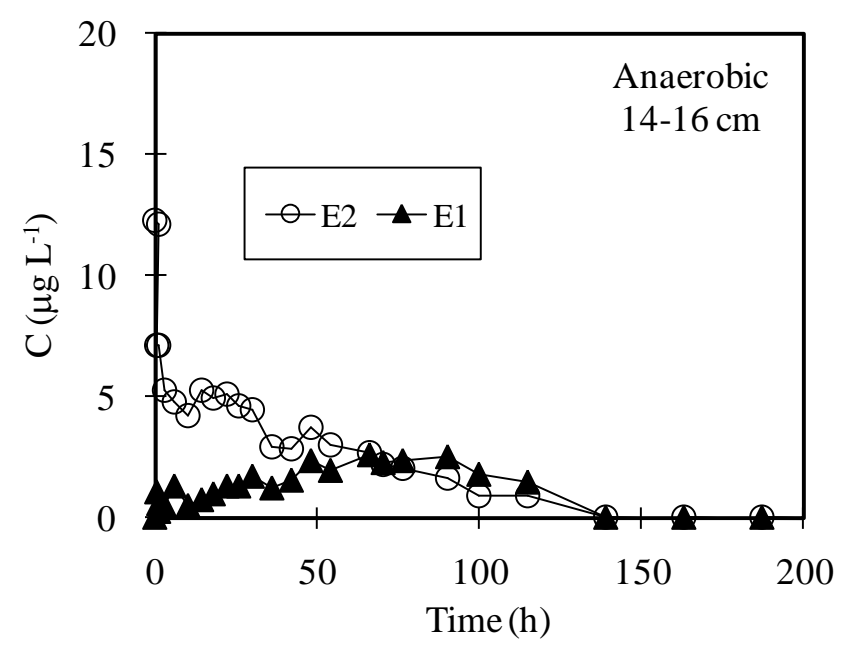

Figure 2 Concentration profiles of E2 and E1 in batch degradation experiments under aerobic and anaerobic conditions for sediment depth at 14-16 $\mathrm{cm}$ of the sediment core.

Indicating rapid decreases at the initial period, E2 dropped to 2.11 and 2.97 $\mu \mathrm{gL}^{-1}$ after being spiked for 36 hours under aerobic and anaerobic conditions, respectively. These represented a reduction of E2 by about 87 and $82 \%$, respectively. Following rapid E2 disappearance at the initial stage, the transformed product of E1 increased and then decreased as E2 turned lower. Once disappeared, both E2 and E1 did not emerge again till the end of the runs that lasted for totally 200 hours. The decreasing profiles of the spiked E2 resembled those obtained in previous studies using activated sludge [7] and 
aquifer material [8].

To further compare the disappearance behavior of E2 under varied depths of sediment, the apparent degradation rate constant of E2 spiked into relative reactors was generated by assuming a first-order reaction. The vertical distribution of the first-order degradation rate constant $(k)$ under aerobic and anaerobic conditions is displayed in Figure 3.

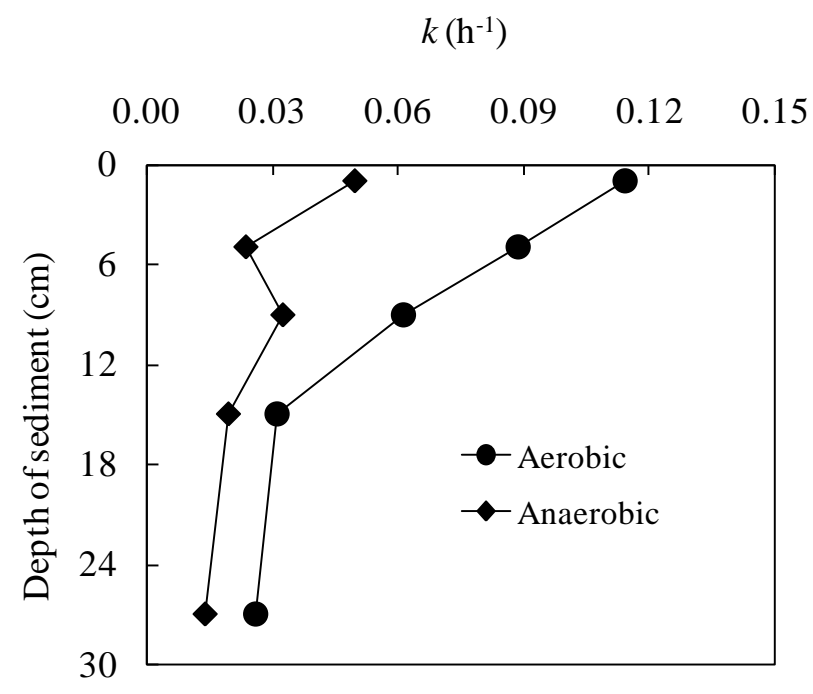

Figure 3 Changes of the apparent first-order degradation rate of E2 along the vertical direction of the sediment core.

The apparent first-order degradation rate constant of E2 from the surface to bottom of sediment layers was estimated falling in the range from 0.114 to $0.026 \mathrm{~h}^{-1}$ under aerobic condition. By conducting transport experiments in columns packed with freshwater sediment from the Mississippi River, Das et al (2004) examined the fate of E2 in a continuous flow mode. The degradation rate with this media was $0.085 \mathrm{~h}^{-1}$, which was $25 \%$ lower than the rate value estimated for the surface sediment layer of the present study $\left(0.114 \mathrm{~h}^{-1}\right)$. This difference was probably due to the differences in the number of active aerobic microbes between sediment sources since, compared to the Mississippi River system, the relatively closed reservoir system created a tranquil water environment that might have been more suitable for microbes' inhabiting and multiplying. Another reason is the different of microbial community composition. This is highly conceivable as one could expect more adapted microorganisms to E2 in reservoir sediments than in soils from agricultural fields because reservoir sediments could contact consistently with water containing trace levels of E2, even if too low to be detected in certain 
circumstances due to the input from sources such as sewage treatment plant (STP) discharge and livestock fields of the surrounding basin areas.

Under anaerobic condition, the apparent first-order degradation rate constant of E2 was estimated fell in the range of 0.05 to $0.014 \mathrm{~h}^{-1}$ from the surface to bottom of sediment layers, which were about 46 to $56 \%$ of the rate values of E2 under the aerobic condition.

\section{Conclusions}

Batch sorption and degradation experiments of natural estrogens were investigated in water-sediment suspensions. The water-sediment partition coefficient of E1 was higher than that of E2. A general trend of enhanced sorption capacity with the total organic carbon content in sorbent material was observed. Under both aerobic and anaerobic conditions, E1 was formed from E2. The apparent first-order degradation rate constant of E2 from the surface to bottom of sediment layers was estimated fell in the range from 0.114 to 0.026

$\mathrm{h}^{-1}$ and 0.05 to $0.014 \mathrm{~h}^{-1}$ under aerobic and anaerobic conditions, respectively. The degradation rate of E2 under aerobic condition was faster than that under anaerobic condition.

\section{Acknowledgement}

This work was supported in part by Grants-in-Aid for Scientific Research (Kiban-B, No. 17360261) from the Japan Society for the Promotion of Science (JSPS).

\section{References}

[1] Isobe, T., Serizawa, S., Horiguchi, T., Shibata, Y., Managaki, S, Takada, H., Morita, M. \& Shiraishi, H., Horizontal Distribution of Steroid Estrogens in Surface Sediments in Tokyo Bay, Environmental Pollution, 144, 632-638, 2006.

[2] Pojana, G., Gomiero, A., Jonkers, N. \& Marcomini, A., Natural and synthetic endocrine disrupting compounds (EDCs) in water, sediment and biota of a coastal lagoon, Environment International, 43, 929-936, 2007.

[3] Tabata, A., Kashiwa, S., Ohnishi, Y., Ishikawa, H., Miyamoto, N. \& Itoh, M., Estrogenic Influence of $17 \beta$-estradiol, P-nonylphenol and Bisphenol $A$ on Japanese Medaka (Oryzias iatipes) at Detected Environmental Concentrations, Water Science and Technology, 43(2), 109-116, 2001.

[4] Peck, M., Gibson, R.W., Kortenkamp, A. \& Hill, E.M., Sediments are Major Sinks of Steroidal Estrogens in two United Kingdom Rivers, Environmental Toxicology and Chemistry, 23, 945-952, 2004 
[5] Das, B.S., Lee, L.S., Rao, P.S.C. \& Hultgren, R.P., Sorption and Degradation of Steroid Hormones in Soils During Transport: Column Studies and Model Evaluation, Environmental Science \& Technology 38(5), 1460-1470, 2004.

[6] Sangsupan, H.A., Radcliffe, D.E., Hartel, P.G., Jenkins, M.B., Vencill, W.K., Cabrera, M.L., Sorption and Transport of $17 \beta$-estradiol and Testosterone in Undisturbed Soil Columns, Journal of Environmental Quality, 35, pp. 2261-2272, 2006.

[7] Li, F.S., Desmiarti, R., Yuasa, A. \& Horio, A., Behavior of Natural Estrogens in Semicontinuous Activated Sludge Biodegradation Reactors, Bioresource Technology, 99, 2964-2971, 2008.

[8] Ying, G.-G., Kookana, R.S. \& Dillon P., Sorption and Degradation of Selected Five Endocrine Disrupting Chemicals in Aquifer Material, Water Research, 37, pp. 3785-3791, 2003. 